\title{
Etik Liderlik Davranışının Bazı Değişkenler Açısından İncelenmesi ${ }^{1}$
}

\author{
Sibel Erol \\ Karabük Üniversitesi \\ Sosyal Bilimler Enstitüsü \\ orcid.org/0000-0003-2448-9042 \\ Halime Göktaş Kulualp* \\ Karabük Üniversitesi \\ Safranbolu Turizm Fakültesi \\ orcid.org/0000-0002-1485-3026
}

\section{Gönderilme Tarihi 10.07.2019 \\ $\underline{\text { Kabul Tarihi }}$ \\ 25.09.2019}

\section{$\ddot{O} z$}

Bu çalışma, yöneticilerde etik liderlik davranışın etkileyen demografik özellikleri belirlemeye yönelik yapılmıştır. Etik, iş dünyasında gün geçtikçe daha da önemli bir konu haline gelmektedir. İşletme içerisinde etik bir ortamın sağlanabilmesi için etik değerleri benimsemiş ve etik liderlik özelliği taşıyan bireylere gereksinim duyulmaktadır. Bu bağlamda, işletmeye etik davranmayı aşılayacak olan yöneticilerdir. Dolayısıyla, öncelikle örgüt içerisinde liderin etik davranması gerekmektedir. Bu amaçla, çalışmada yöneticilerin etik liderlik özelliklerini etkileyen bazı değişkenler belirlenmeye çalışılmıştır. Çalışmanın veri seti 389 otel yöneticisinden oluşmaktadır. Elde edilen verilerin analizinde t-testi, Anova ve Tukey testleri kullanılmıştır. Etik liderlik ile mezuniyet durumu, işletmedeki konum ve işletmenin bulunduğu il değişkenleri arasında anlaml ilişkiler tespit edilmiştir. Fakat, cinsiyet, medeni durum, işletmenin türü değişkenlerinin etik liderlik üzerinde anlamlı bir etkisi bulunmamaktadır.

Anahtar Kelimeler: Etik Liderlik, Demografik Değişkenler, Yönetici, Turizm Sektörü.

\section{An Investigation of Ethical Leadership Behavior with Respect to Some Variables}

\begin{abstract}
This study was conducted to determine the demographic characteristics that affect the ethical leadership behavior of managers. Ethics has become an important issue in the business world. In order to provide an ethical ethical environment, individuals who adopt ethical values and have ethical leadership characteristics are needed. In this context, they are managers who will instill ethical behavior in the enterprise. Therefore, the leader must act ethically in the organization. For this purpose, some variables that affect the ethical leadership characteristics of managers have been tried to be determined. The data set of the study consists of 389 hotel managers. The t-test, Anova and Tukey tests were used to analyze the data. Significant relationships were found between ethic leadership and graduation status, location in the enterprise and province where the enterprise was located. However, gender, marital status, type of business have no significant effect on ethical leadership.
\end{abstract}

Keywords: Ethical Leadership, Demographic Variables, Manager, Tourism Sector.

\section{Giriş}

Etik kelimesi yaşamın her alanında karşımıza çıkmaktadır. Özellikle iş alanında etik değerler önemli bir unsur olarak değerlendirilmektedir. Etik değerleri benimserken iş görenler kendilerine bir yol gösterici aramaktadır. Bu yol göstericiler de genellikle üst düzey bir yönetici veya çalışanın yakınındaki alt düzey yöneticilerden oluşmaktadır. Bu nedenle etik, bireylerin iş yaşantısında ve özel yaşantısında neyi yapması gerektiğini ve nasıl yapması gerektiğini, hangi davranışların hayati öneme sahip olduğunu gösteren önemli bir değerdir (Sezgül, 2010: 244).

\footnotetext{
${ }^{1}$ Bu çalışma Karabük Üniversitesi Turizm İşletmeciliği Anabilim Dalı'nda yapılan "Duygusal Zekânın Etik Liderlik Davranışı Üzerindeki Etkisi: Turizm İşletmeleri Yöneticileri Üzerine Bir Uygulama" isimli yüksek lisans tezinden üretilmiştir.

*Yazışma adresi. Email: halimegoktas@karabuk.edu.tr
} 
Etik liderlik organizasyonlar için hayati önem taşımaktadır (Coyne ve Bell ve Merrington, 2013: 27). Etik liderler örgütteki çalışanlara karşı oldukça dürüstlerdir ve karşılarındakilerin de dürüst olmasını beklerler. Yaptıkları her işe etik değerler düzeyinde önem verirler (Sezgül, 2010: 245). Etik liderlik özelliği taşıyan yöneticiler işgörenlerine ahlaki açıdan örnek olurlar. Onları motive ederler. Verdikleri kararlar ve uyguladıkları arasında tutarlılık söz konusudur. Etik liderler hiçbir koşulda dürüstlükten taviz vermezler (Aslantaş ve Dursun, 2006: 113). Etkili bir etik lider ahlaki açıdan inandırıcı bir rol model olmalıdır. Adil, dürüst ve başkalarını önemseyen lider başkaları tarafından önemsenir. Liderler eğer bu bahsedilen olgulara sahip değillerse takipçileriyle etkileşimleri zayıf, başarısız ve tutarsız lider olurlar (Brown ve Mitchell, 2010: 584). Etik lider, etik standartların anlaşılması, desteklenmesi ve benimsenmesine odaklanmıştır. Bu liderler, örgütteki kişilerin etik standartlara uygun davranmalarını sağlarlar. Etik liderler örgütteki çalışanlara karşı oldukça dürüstlerdir ve karşılarındakilerin de dürüst olmasını beklerler. Yaptıkları her işe etik değerler düzeyinde önem verirler (Sezgül, 2010: 245). Etik liderlik örgütün ayakta kalabilmesi, büyümesi ve uzun vadede etkililiğini arttırması için gereklidir (Pickeet, 2005: 44).

Etik; bireylerin insan ilişkilerinde nasıl davranmaları gerektiğini belirleyen değerlerdir (Coyne ve Bell ve Merrington, 2013: 31). Lider; bireyleri etkileyebilen ayrica başka bireylere ait yetenek ve beceriler ile kendi yetenek ve becerilerine odaklanan kişidir. Alçakgönüllü olan liderler takipçilerinin inanç ve değerlerine saygı gösterirler. Örgüte ait misyon ve vizyonu takipçilerine benimsetirler (Winston ve Patterson, 2006: 6). Etik liderlik ise kişilerarası ilişkilerde normatif değerlere uygun bir biçimde yönetim tarzı sergileyebilen ve bu yönetim tarzını güçlendirebilen ahlaki düşünme biçimini benimsemiş liderliktir (Tuna ve Yeşiltaş, 2013:191). Etik liderler uzun vadeli düşünen, doğru kararlar alarak aldıkları bu kararların sonuçlarını kabullenen, mütevazı, adil, sorumluluk sahibi, saygılı kişilerdir (Mihelic ve Lipicnik ve Tekavcic, 2010: 31).

Örgütler belirledikleri misyon ve vizyonlarına ulaşabilmek adına etik değerlere önem vermelidir. Etik değerleri ihlal ettikleri durumlarda örgütün maddi ver manevi kayıplarının olabileceğini ön görmelilerdir. Örgütün bu tür olumsuzluklara uğramaması için örgütte görevli yöneticilerin etik liderlik özelliği taşımaları gerekmektedir (Dertli, 2014: 23). Etik değerlere önem vermeyen işletmeler birçok olumsuzlukla kaşılaşabileceklerdir. Etik değerleri ihlal ettikleri için hedefledikleri karlılığ1 yakalayamayacaklardır (Monahan, 2012: 57). İşletmeler amaçlarına ulaşabilmek ve kârlılığını arttırabilmek amacıyla etik değerleri benimsemelidir (Yavuz, 2015: 5). Bahsedilen ve yöneticilerde bulunması gereken bu etik değerler; olumlu insan ilişkileri, açıklık, insancıl (hümanist) olma, bağlı olma, hukukun üstünlügünü kabullenme, sevgi-saygı ve hoşgörü ile demokrasi, hak ve özgürlükleri savunma, emeğe saygılı olma ve hak edileni sunma, adil, laik, insan haklarına bağlı, dürüstlük ve doğruluk ilkesini benimsemiş, tarafsız ve sorumluluk bilincinde olma ve yasal olmayan emirlere karşı direnme şeklinde sıralanabilir (Aksoy, 2012: 18). Etik liderler içerisinde bulundukları örgütte yer alan tüm çalışanlara karşı dürüst ve adildirler. Yaptıkları her işte etik değerlere önem gösterirler (Sezgül, 2010: 245). Ahlaki açıdan da 
örnek olan etik liderler dürüstlükten asla taviz vermezler (Aslantaş ve Dursun, 2006: 113).

Turizm gibi emek yoğun hizmet sektörlerinde adil olma, dürüst ve tarafsız olma iş kalitesini arttırmak için önemi bir unsur niteliğinde olabilir (Ural, 2003; Çevirgen ve Üngüren, 2009). Tarafsız olan, iş görenine adil davranan bir işletme yöneticisinin içinde bulunduğu örgütün başarısız olma ihtimali düşüktür (Barutçugil, 2004; Özkalp ve Kırel, 2005). Yapılan bu araştırmanın amacı, turizm işletmelerinde görevli yöneticilerin etik liderlik tarzlarının demografik değişkenlere göre farklılık gösterip göstermediğini belirlemektir.

\section{Etik Liderlik}

Etik liderlik; kişisel eylemler ile kişilerarası ilişkileri uyumlu bir şekilde kullanarak takipçileri ile iyi ilişki kurabilen ve olumlu kararlar alabilen kişilere yöneliktir (Fred, vd. 2011: 204). Etik lider cesaret verici, yol gösterici ve güçlendirici özelliğe sahiptir. Çalışanlarını teşvik ederek onlara sorumluluk duygularının kazandırıp çalışanların kendi kendilerine yeterli olmalarını sağlar (Christian, vd. 2006: 347). Etik liderler yapılacak en doğru şeyin ne olduğu ile ilgilenip bu soruya odaklanırlar (Mayer ve Kuenzi ve Greenbaum, 2010: 8). Yapacakları her eylemde başkalarının onur ve haysiyetine önem gösterirler. Başkalarının onur ve haysiyetlerine saygılı bir şekilde işlerini gerçekleştirirler. Bu hareketleri ile hem işletme karlılığını arttırıp hem de işletmelerine ve kendilerine toplumsal değer kazandırırlar (Ponnu ve Tennakoon, 2009: 22). Takipçilerine karşı kaliteli ilişkiler oluşturan etik liderlerin karar ve davranışları takipçilerine yöneliktir. Bu durum da etik lider ve takipçileri arasındaki iişkiyi güçlendirmektedir (Heres, 2010: 4).

Etik liderler, etik ilkeleri benimsemelidir. Bu etik ilkelerin benimsenebilmesi için uygun bir kurum kültürünün oluşmuş olması gerekir. Etik değerlere sahip olan yönetici için uygun bir etik kültürü yok ise liderler bu kültürü kendileri oluşturmalıdır. Kurum kültürünün güçlü ya da zayıf olması liderin etkinliğini belirlemektedir (Çengelci, 2014: 22).

Etik liderlerin sahip olması gereken birtakım özelikler bulunmaktadır. Bu özellikler (Aksoy, 2012: 27);

- Organizasyonda etik standartların uygulanmasını sağlamak ve bu konuda çalışanlara destek olmak,

- Örgütte yer alan çalışanların etik davranışlar sergilemesine destek olmak ve etik değerleri ihlal eden işgörenlere karşı hoş görülü olmamak,

- Başkalarına bu etik standartlar konusunda örnek olmak,

- Karar verirken etik standartlara karşı hassas olmak ve kararlarının sonuçların etik açıdan sorgulamak,

- Çalışma süresince etik standartlara uygun davranan çalışanlara öncelik vererek çalışanlara her zaman yol gösterici olmak, olarak sıralanmaktadır.

Literatüründe etik liderlikle ilgili yaklaşımlar, Burns'un Etik Liderlik Yaklaşımı ve Heifetz'in Etik Liderlik Yaklaşımı şeklinde sıralanmaktadır. Burns'un Etik Liderlik 
Yaklaşımı, Burns tarafından geliştirilmiştir. Bu yaklaşıma göre; liderlere ait temel rol, ahlaki sorunlara ve konulara yönelik farkındalık yaratma ve kişiler arası çatışma durumunu analiz etmedir. Liderler açgözlülük, korku, kin gibi olumsuz duyguları bir tarafa bırakarak eşitlik, adalet, özgürlük, hümanizm ve barış gibi ahlaki değerleri benimser ve astlarının bu değerleri geliştirmesi için çaba gösterir (Güney, 2006: 140). Heifetz'in Etik Liderlik Yaklaşımı ise Ronald Heifetz tarafından 1994 yılında "Leadership Without Easy Answers" adlı kitapta konu edilmiştir. Bu yaklaşıma göre liderin temel görevi, işgörenlerine çatışma durumlarında yardımcı olma, çatışma durumunu çözme ve çatışma durumunu etkin bir şekilde yönetme ile verimli çözümler üretme olarak belirlenmiştir. Liderler sorunların çerçevesini belirleyip, çatışmalar ile ilgilenir. Kişi ya da gruplara bu sorunlar ile ilgili belirli sorumluluk yüklemektedir (Güney, 2006: 141). Ronald Heifetz'e göre lidere ait belirli sorumluluklar vardır. Bunlar çalışanlar arasındaki çatışmaları çözme ve çatışma sonrasında ortaya çıkan değişimleri yönetebilme olarak ifade edilmiştir (Dertli, 2014: 28).

\section{Araştırmanın Metodolojisi}

\subsection{Araştırmanın Amacı}

Çalışma kapsamında, etik liderlik davranışının demografik değişkenlere göre farklılaşıp farklılaşmadığı araştırılmıştır. Literatüre etik liderlik konusunda katkı sağlayarak turizme yeni araştırma alanı oluşturmak amaçlanmıştır. Ayrıca turizm yöneticilerinin etik liderlik ile ilgili farkındalığını arttırmakta bu araştırmanın amaçlarındandır.

\subsection{Araştırmanın Evren ve Örneklemi}

Araştırmanın evreni, Batı Karadeniz bölgesi turizm işletmeleri yöneticilerinden oluşmaktadır. Tüm turizm işletmelerine ulaşılabilirliğin güç olması ve finansal kaynak eksikliği nedeniyle ayrıca veri toplamada sıkıntılar oluşabileceği için araştırma TR81 Düzey 2 bölgesi olarak sınırlandırılmıştır. Araştırmanın yapıldığı iller, belirtilen kısıtlardan dolayı, kolayda örnekleme şeklinde belirlenmiştir.

Batı Karadeniz Bölgesinde yer alan toplam tesis sayısı 558'dir TR 81 Düzey 2 illerinde toplam tesis sayısı 207'dir. Belediye belgeli konaklama tesislerinde (165x3) 495, Turizm işletme belgeli tesislerde (42x5) 210 yönetici, toplamda 705 yönetici olduğu varsayılmıştır. 700 kişilik ana kütle büyüklügüünü temsil edecek örneklem büyüklüğü 248' dir (Sekaran, 2003). Ulaşılan cevaplayıcı sayısı 389'dur. Dolayısıyla, ulaşılan örneklem sayısının evreni temsil ettiği söylenebilir. Genel anlamda araştırma sorusu, etik liderliğin hangi demografik değişkenlere göre nasıl bir farklılık gösterdiği üzerine odaklanmaktadır.

\subsection{Araştırmanın Hipotezleri}

Çalışmanın amacına dayalı olarak aşağıdaki hipotezler oluşturulmuştur:

- H1: Yöneticilerin etik liderlik davranışları cinsiyet değişkenine göre farklılık göstermektedir.

- H2: Yöneticilerin etik liderlik davranışları yaş değişkenine göre farklılık göstermektedir. 
- H3: Yöneticilerin etik liderlik davranışları medeni durum değişkenine göre farklılık göstermektedir.

- H4: Yöneticilerin etik liderlik davranışları mezuniyet durumu değişkenine göre farklılık göstermektedir.

- H5: Yöneticilerin etik liderlik davranışları işletmenin bulunduğu il değişkenine göre farklılık göstermektedir.

- H6: Yöneticilerin etik liderlik davranışları hukuki yapı değişkenine göre farklılık göstermektedir.

- H7: Yöneticilerin etik liderlik davranışları yöneticilik deneyimi değişkenine göre farklılık göstermektedir.

- H8: Yöneticilerin etik liderlik davranışları işletmenin konumu değişkenine göre farklılık göstermektedir.

\subsection{Araştırmada Kullanılan Ölçekler}

Araştırmada, Etik liderliği ölçmek için Türkçe kullanımına uygunluğu, geçerliliği ve güvenirliliği Tuna ve diğerleri (2012) tarafından gerçekleştirilen Brown vd. (2005) nin geliştirdikleri 10 ifadeden oluşan ölçek kullanılmıştır. Ölçek (1) Hiç Katılmıyorum, (2) Az Katılıyorum, (3) Orta Düzeyde Katılıyorum (4) Çok Katılıyorum, (5) Tamamen Katılıyorum ifadelerinden oluşan 5'li Likert ölçek şeklinde kullanılmıştır. Brown vd. (2005)'nin geliştirdikleri bu 10 ifadeli ölçeğin etik liderliği ölçmek için güvenilir bir ölçek olduğu kabul edilmiştir (Yeşiltaş ve Çeken ve Sormaz, 2012: 26; Arslantaş ve Dursun 2008: 117).

\subsection{Veri Toplama ve Analiz Yöntemi}

Araştırmada Bartın, Karabük ve Zonguldak illerinde görev yapan 389 otel yöneticisinden veri toplanmıştır. Tanımlayıcı özelikler, frekans ve yüzde istatistikleri, etik liderlik düzeylerini belirlemek amaciyla ise ortalama ve standart sapma istatistikleri yapılmıştır. Yöneticilerin demografik değişkenlere göre etik liderlik özelliklerinin farklılaşmasının incelenmesinde t-testi, Tek Yönlü Anova ve Tukey testlerinden yararlanılmıştır.

\section{Araştırmanın Bulguları}

\subsection{Faktör Analizi ve Güvenilirlik Analizi Sonuçları}

Etik liderlik ölçeğine ait güvenilirlik analizi sonuçları incelendiğinde etik liderlik ölçeğinin genel güvenilirlik katsayısı (Cronbach's Alpha) $\alpha=0,744$ olarak hesaplanmıştır. Etik liderlik ölçeğinin Kaiser-Meyer-Olkin değeri örneklem hacminin yeterliğini $(\mathrm{KMO}=0,743)$, Bartlett testi ise faktör analizinin uygulanabilirliğini $(\chi 2$ $=2568,755 ; \mathrm{p}<0,000)$ ortaya koymuştur. Ölçekte yer alan ifadeler tek bir boyut altında toplanmiştır.

\subsection{Katılımcıların Demografik Özelliklerine İlişkin Bulgular}

Araştırma kapsamına giren yöneticilerin \%33,7'si kadın, \%66,3'si erkektir. Katılımcıların \%38'i 37-47 yaş arasındadır. Araştırmaya dâhil olan katılımcıların $\% 64,3$ 'ü evlidir. Araştırmaya katılan yöneticilerin \%45'i lise eğitim seviyesine sahiptir. Yöneticilerin sektörel deneyimleri incelendiğinde yöneticilerin \%53,7'si 11 yıl ve üzeri 
deneyime sahiptir. Araştırma \%48,8 ile üst kademe yönetici, \%40,4 ile alt kademe yöneticilerden oluşmaktadır. Yöneticilerin \%32,4'ü Bartın, \%24,22'si Zonguldak, \%43,4'ü Karabük illerinde çalışmaktadır. İşletmenin Hukuki Yapısı incelendiğinde örneklemi oluşturan bölgedeki yöneticilerin \%40,1 Turizm İşletme Belgeli, \%59,9 Belediye Belgeli konaklama tesisinde çalışmaktadır.

\subsection{Hipotezlerin Test Edilmesine İlişkin Bulgular}

$\mathrm{Bu}$ bölümde hipotezleri test etmek amacıyla etik liderlik ölçeğine ilişkin analizlere yer verilmiştir. Demografik değişkenler ile etik liderliğe ilişkin t-testi analiz sonuçları Tablo 1'de yer almaktadır.

Tablo 1. Etik Liderlik ile Cinsiyet, Medeni Durum, İşletmenin Hukuki Yapısı

Değişkenleri Arasındaki Farklılı̆̆ın İncelenmesi

\begin{tabular}{|c|c|c|c|c|c|c|}
\hline Boyutlar/Faktörler & Değişkenler & Gruplar & Ort $\bar{X}$ & s.s. & $\mathbf{t}$ & $\mathbf{P}$ \\
\hline \multirow{6}{*}{ Etik Liderlik } & \multirow{2}{*}{ Cinsiyet } & Kadın & 3,49 & 0,71 & \multirow{2}{*}{1,02} & \multirow{2}{*}{0,30} \\
\hline & & Erkek & 3,41 & 0,71 & & \\
\hline & \multirow{2}{*}{ Medeni Durum } & Evli & 3,45 & 0,73 & \multirow{2}{*}{0,32} & \multirow{2}{*}{0,74} \\
\hline & & Bekâr & 3,42 & 0,68 & & \\
\hline & \multirow{2}{*}{$\begin{array}{l}\text { İşletmenin Hukuki } \\
\text { Yapısı }\end{array}$} & Turizm İşletme Belgeli & 3,39 & 0,79 & \multirow{2}{*}{1.11} & \multirow{2}{*}{0,26} \\
\hline & & Belediye Belgeli & 3,47 & 0,66 & & \\
\hline
\end{tabular}

${ }^{*} \mathrm{p}<0,05$

Etik liderliğin cinsiyet, medeni durum ve işletmenin hukuki yapısı değişkenleri ile oluşturulan t-testi sonuçlarına göre; etik liderlik boyutu ile cinsiyet değişkeni arasında $(\mathrm{p}=0,30 ; \mathrm{p}>0,05)$ düzeyinde, etik liderlik ile medeni durum değişkeni arasında $(\mathrm{p}=0,74 ; \mathrm{p}>0,05)$ düzeyinde ve etik liderlik ile işletmenin hukuki yapısı değişkenleri arasında $(p=1,11 ; p>0,05)$ düzeyinde anlamlı bir farklılık tespit edilememiştir. $\mathrm{Bu}$ durumda ankete katılım sağlayan yöneticilerin kadın veya erkek olması, evli veya bekar olması, turizm işletme belgeli veya belediye belgeli tesislerde çalışması etik liderliği etkilememektedir.

Araştırmada etik liderlik ile demografik değişkenler arasındaki farklılığ belirlemek amaciyla Anova ve Tukey testlerinden de yararlanılmış ve analiz sonuçları Tablo 2'de sunulmuştur. 
Tablo 2. Etik Liderliğin Demografik Değişkenler ile Karşılaştırılması

\begin{tabular}{|c|c|c|c|c|c|c|c|}
\hline $\begin{array}{l}\text { Boyutlar/ } \\
\text { Faktörler }\end{array}$ & Değişkenler & Gruplar & Ort $\bar{X}$ & s.s. & $\mathbf{F}$ & p & Tukey \\
\hline \multirow{18}{*}{$\begin{array}{l}\text { Etik } \\
\text { Liderlik }\end{array}$} & \multirow{4}{*}{$\begin{array}{l}\text { Mezuniyet } \\
\text { Durumu }\end{array}$} & İlköğretim & 3,61 & 0,72 & \multirow{4}{*}{5,86} & \multirow{4}{*}{$0,00^{*}$} & \multirow{4}{*}{$2-4$} \\
\hline & & Lise & 3,30 & 0,67 & & & \\
\hline & & Ön lisans & 3,42 & 0,70 & & & \\
\hline & & $\begin{array}{l}\text { Lisans ve } \\
\text { üzeri }\end{array}$ & 3,67 & 0,74 & & & \\
\hline & \multirow{5}{*}{ Yaş } & 25 ve altı & 3,43 & 0,58 & \multirow{5}{*}{1,26} & \multirow{5}{*}{0,28} & \multirow{5}{*}{-} \\
\hline & & $26-36$ & 3,40 & 0,70 & & & \\
\hline & & $37-47$ & 3,38 & 0,74 & & & \\
\hline & & $48-58$ & 3,49 & 0,71 & & & \\
\hline & & 59 ve üstü & 3,65 & 0,67 & & & \\
\hline & \multirow{3}{*}{$\begin{array}{l}\text { İşletmedeki } \\
\text { konum }\end{array}$} & Üst Kademe & 3,47 & 0,69 & \multirow{3}{*}{4,24} & \multirow{3}{*}{$0,01^{*}$} & \multirow{3}{*}{$2-3$} \\
\hline & & Orta Kademe & 3,68 & 0,76 & & & \\
\hline & & Alt Kademe & 3,33 & 0,71 & & & \\
\hline & \multirow{3}{*}{$\begin{array}{l}\text { Yöneticilik } \\
\text { Deneyim }\end{array}$} & $1-5$ yil & 3,35 & 0,65 & \multirow{3}{*}{0,80} & \multirow{3}{*}{0,44} & \multirow{3}{*}{-} \\
\hline & & 6-10 y1l & 3,47 & 0,75 & & & \\
\hline & & 11 yıl ve üzeri & 3,45 & 0,72 & & & \\
\hline & \multirow{3}{*}{$\begin{array}{l}\text { İşletmenin } \\
\text { Bulunduğu İl }\end{array}$} & Bartın & 3,43 & 0,64 & \multirow{3}{*}{17,75} & \multirow{3}{*}{$0,00^{*}$} & \multirow{3}{*}{$1-2,2-3$} \\
\hline & & Zonguldak & 3,78 & 0,67 & & & \\
\hline & & Karabük & 3,25 & 0,72 & & & \\
\hline
\end{tabular}

$\mathrm{p}<0,05$ (1: İlköğretim, 2: Lise, 3: Önlisans, 4: Lisans ve üzeri) 1,2,3,4 gruplar arasındaki fark önemlidir. $\mathrm{p}<0,05$ (1: 205 ve altı, 2: 26-36 yaş, 3: 37-47 yaş, 4: 48 yaş ve üzeri) 1,2,3,4 gruplar arasındaki fark önemlidir. $\mathrm{p}<0,05$ (1: Üst Kademe, 2: Orta Kademe, 3: Alt Kademe) 1, 2,3 gruplar arasındaki fark önemlidir. $\mathrm{p}<0,05$ (1: 1-5 yıl, 2: 6-10 yıl, 3: 11 yıl ve üzeri) ${ }^{1,2,3}$ gruplar arasındaki fark önemlidir.

Etik liderlik ile demografik değişkenler incelendiğinde mezuniyet değişkeninin $\left(\mathrm{F}=5,86 \mathrm{p}=0,00^{*}\right)$ etik liderlik davranışı sergilemede farklılığa yol açtığ edilmiştir. Bu farklılığın hangi gruplar arasında oluştuğunu ortaya koymak amacıyla yapılan Tukey testi sonucuna göre $(\bar{X}=3,67)$ lisansüstü eğitim seviyesindeki yöneticinin $(\bar{X}=3,30)$ lise eğitim seviyesindeki yöneticilere göre daha fazla etik liderlik davranış sergilediği söylenebilmektedir.

İşletmedeki konum değişkeninin etik liderlik davranışı sergilemeye göre farklılığ1 incelendiğinde $\left(\mathrm{F}=4,24 \mathrm{p}=0,01^{*}\right)$ düzeyinde farklılık görülmektedir. $\mathrm{Bu}$ farklılığın hangi değişkenlerden kaynaklandığını görmek için yapılan Tukey testi sonucuna göre alt kademe yöneticiler ile orta kademe yöneticiler arasında farklılık görülmektedir. Aritmetik ortalama değeri $(\bar{X}=3,68)$ olan orta kademeli yöneticiler alt kademe yöneticilere göre daha fazla etik liderlik özelliğini taşımaktadır.

Etik liderlik ile işletmenin bulunduğu il değişkeni arasında $(F=17,75$ p=0, 00) düzeyinde anlamlı bir farklılık bulunmuştur. Yapılan Tukey testi sonucuna göre $(\bar{X}=3$, 78) aritmetik ortalama değeri ile Zonguldak ilindeki yöneticilerin Bartın ve Karabük illerindeki yöneticilere göre daha fazla Etik liderlik özelliği taşıdıkları söylenebilmektedir. 
Yapılan araştırmada etik liderlik yaş değişkeni ve yöneticilik deneyimi değişkenine göre farklılık göstermemektedir.

\section{Sonuç ve Öneriler}

Emek yoğun bir sektör olan turizm sektöründe işgörenlerin daha verimli ve işletmenin hizmet kalitesinin üst düzey olabilmesi için yöneticilerin belirli liderlik vasıflarına sahip olması gerekmektedir. Liderlik vasfına sahip olmayan bir yöneticinin bulunduğu turizm işletmelerinde her zaman yolunda gitmeyen birtakım olaylar olacaktır. Elbette ki liderlik vasfına sahip yöneticinin de bulunduğu işletmede çeşitli olumsuzluklar yaşanacaktır. Fakat liderlik vasfı gelişmiş bir yönetici bu olumsuzlukları etkili bir şekilde ortadan kaldırma konusunda yetenekli bir yapıya sahip özellik göstererek işgörenlerin ve müşterilerin takdirini kazanacaktır.

Etik liderler, örgütte yer alan işgörenlerin davranışlarını yönlendiren, etik standartları geliştiren ve bu standartları uygulayan kişilerdir (Çengelci, 2014: 1). Etik liderlik örgütün ayakta kalabilmesi, büyümesi ve uzun vadede etkililiğini koruması ve arttırması için gerekli bir liderlik türüdür (Pickeet, 2005: 44). Etik liderler grubunda yer alan kişilerin hak ve onurlarına saygılı bir şekilde hareket edebilen kişilerdir (Christian, vd. 2006: 346). Çalışma yaşamı boyunca etik değerlerden vazgeçmeyerek bu etik değerleri kullanan yöneticiler, çalışanlarının motivasyonlarını arttırarak onların performansının en üst düzeye çıkmasını sağlayacaklardır. Aynı şekilde duygusal zekâsı yüksek yöneticiler de karşısındaki insanların duygu ve düşüncelerini en iyi şekilde anlayarak etkili kararlar verebileceklerdir. Dolayısıyla turizm sektörü gibi insan memnuniyetinin hedeflendiği tüm sektörlerde bu durum kaçınılmaz olmaktadır.

Etik, yaşamın her alanında önemsenmesi gereken bir değerdir. İşletmelerin verimliliğini arttırması ve çalışanların örgüte değer vermesi için etik standartların benimsenmesi gereklidir. Bu nedenle de etik liderlik işletmeler için hayati öneme sahiptir. Etik liderlik özelliğine sahip bir yönetici yaşamının her alanında etik değerleri benimseyerek bu etik değerleri geliştirici düzenlemeleri araştırır. Çalışanlarına karşı adil ve hoşgörülü yaklaşan etik lider her çalışanına aynı muameleyi göstererek çalışanlar arasında meydana gelen anlaşmazlıkları tarafsız bir şekilde çözüme kavuşturur. Bu sayede de örgüt motivasyonunu her zaman yüksek tutar.

Araştırma TR81 Düzey 2 illerinde görevli turizm işletmeleri yöneticilerinin etik liderlik tarzını etkileyen demografik değişkenleri belirlemeye yönelik yapılmıştır. Araştırma bulgularından elde edilen sonuçlar doğrultusunda lisansüstü eğitim seviyesindeki yöneticinin daha fazla etik davranış sergilediği söylenebilmektedir. Ĕ̆itim seviyesindeki artışın, etik liderlik davranışı sergilemeyi de pozitif yönde etkilediğinden söz edilebilir. Aynı şekilde orta kademeli yöneticilerin alt kademe yöneticilere göre daha fazla etik liderlik özelliğini taşıdığı araştırma sonuçlarından elde edilmiştir. Bu durum yöneticilik kademesi arttıkça etik değerlere sahip çıkma anlayışının da arttığı düşüncesini ortaya çıkarabilir. Araştırma kapsamına giren TR81 Düzey 2 illerinden Zonguldak ilindeki yöneticiler Bartın ve Karabük ilinde görevli yöneticilere göre daha fazla etik liderlik özelliği taşımaktadır. Araştırmanın literatüre 
katkı sağlaması beklenmektedir. Araştırma farklı turistik alanlar ya da farklı sektörlerde uygulanarak farklı bulgular elde edilebilir.

\section{Kaynakça}

Aksoy, S. (2012). Etik liderlik ve örgütsel vatandaşlık davranışlarının örgütsel performansa etkisi üzerine bir araştırma. Gebze Yüksek Teknoloji Enstitüsü Sosyal Bilimler Enstitüsü İşletme Anabilim Dalı, (Yayınlanmamış Yüksek Lisans Tezi), Gebze/ Kocaeli.

Arslantaş, C. ve Dursun, M. (2008). Etik liderlik davranışının yöneticiye duyulan güven ve psikolojik güçlendirme üzerindeki etkisinde etkileşim adaletinin dolaylı rolü. Anadolu Üniversitesi Sosyal Bilimler Dergisi 1(8), 111-128.

Barutçugil, İ. (2004). Stratejik İnsan Kaynakları Yönetimi. 1. Baskı, İstanbul: Kariyer Yayıncılık.

Brown, M. E ve Mitchell, M.S. (2010). Ethical and unethical leadership: exploring new avenues for future. Research Business Ethics Quarterly, 4(20), 583-616.

Christian J. Resick, C. J., . Hanges, P. J., Dickson, M.V. ve Mitchelson, J. K. (2006). A crosscultural examination of the endorsement of ethical leadership. Journal of Business Ethics (63), 345-359, DOI 10.1007/S10551-005-3242-1.

Coyne, J., Bell, P., ve Merrington, S. (2013). Exploring ethics in intelligence and the role of leadership. International Journal of Business and Commerce, 10(2), 27-32.

Çengelci, E. (2014). Okul yöneticilerinin etik liderlik davranışları. Afyon Kocatepe Üniversitesi Sosyal Bilimler Enstitüsü Eğitim Bilimleri Anabilim Dalı, (Yayınlanmamış Yüksek Lisans Tezi), Afyon.

Çevirgen, A., ve Üngüren, E. (2009). Konaklama İşletmelerinde Etik İklim ve İş Tatmini İlişkisi. 10. Ulusal Turizm Kongresi, 21-24.

Dertli, E. M. (2014). Etik liderlik davranışlarının ve iş tatmininin çalş̧anların tükenmişlik duygularına etkisi: amprik bir çalışma. Beykent Üniversitesi Sosyal Bilimler Enstitüsü İşletme Yönetimi Anabilim Dalı İnsan Kaynakları ve Örgütsel Değişim Bilimi, (Yayınlanmamış Yüksek Lisans Tezi), İstanbul.

Fred O., Walumbwa, F.D., Mayer, D. M., Peng Wang, P., Wang, H., Workman, K. \& Christensen, A.L. (2011). Linking ethical leadership to employee performance: the roles of leader-member exchange, self-efficacy, and organizational identification, Organizational Behavior and Human Decision Processes, (115), 204-213.

Güney, S. (2006). Ahlaki liderligin kavramsallastırılması ve ahlaki yönetimde liderligin rolü, Yönetim ve Ekonom Dergisi, 13(1), 135- 148.

Heres, L. (2010). Ethical leadership: a varıform universal phenomenon https://Www.Law.Kuleuven.Be/Integriteit/Egpa/Egpa2010/Heres Lasthuizen_EthicalLeadership-A-Variform.Pdf (Erişim: 30.05.2016).

Mayer, D.M., Kuenzi, M. ve Greenbaum R. L. (2010). Examining the link between ethical leadership and employee misconduct: the mediating role of ethical climate. Journal of Business Ethics (95), 7-16.

Mihelič, K. K., Lipičnik, B. ve Tekavčič, M. (2010). Ethical leadership. International Journal of Management E Information Systems Fourth Quarter, 5(14), 31-42. 
Monahan, K. (2012). A review of the literature concerning ethical leadership in organizations. Emerging Leadership Journeys, (5)1, 56-66.

Pickett, M. C. (2005). Understandıng ethical leadership. Asbbs E-Journal, 1(1), 44- 54.

Ponnu, C.H. ve Tennakoon, G. (2009). The association between ethical leadership and employee outcomes-the malaysian casen. Electronic Journal of Business Ethics and Organization Studies, 1(14), 21-32.

Sezgül İ. (2010). Liderlik ve etik: geleneksel, modern ve postmodern liderlik tanımları bağlamında bir değerlendirme. Toplum Bilimleri Dergisi, 4(7), 239-251.

Tuna, M. ve Yeşiltaş, M. (2013). Liderliğin etik boyutu: etik liderliğin otel işletmelerindeki iş görenler tarafından algılanması. İşletme Araştırmaları Dergisi, 3(5), 184-209.

Tuna, M., Bircan, H., ve Yeşiltaş, M. (2012). Etik liderlik ölçeğinin geçerlilik ve güvenilirlik çalışması: antalya örneği.

Özkalp, E. ve Kırel, Ç. (2005). Örgütsel Davranış. Eskişehir: Anadolu Üniversitesi Yayınları. Atatürk Üniversitesi IIBBF Dergisi, 26(2), 143-156.

Ural, T. (2003). İşletme ve Pazarlama Etiği. Ankara: Detay Yayıncılık.

Winston, B. E ve Patterson, K. (2006). An integrative definition of leadership. International Journal of Leadership Studies, (1)2, 6-66. ISSN 1554-3145.

Yavuz, N. (2015). Çalışanların etik liderlik algılamalarının iş tatminini arttırma yönündeki etkisi: telekomünikasyon firmasında amprik bir çalışma. Bahçeşehir Üniversitesi Sosyal Bilimler Enstitüsü İnsan Kaynakları ABD, (Yayınlanmamış Yüksek Lisans Tezi), İstanbul.

Yeşiltaş, M. Çeken, H., ve Sormaz, Ü. (2012). Etik liderlik ve örgütsel adaletin örgütsel sapma davranışları üzerindeki etkisi. Muğla Üniversitesi Sosyal Bilimler Enstitüsü Dergisi, (28), 17-39. 